\title{
CLINICAL PATTERN OF LIVER ABSCESS AMONG THE PATIENTS ADMITTED IN RAJSHAHI MEDICAL COLLEGE HOSPITAL
}

\author{
CHANCHAL KUMAR GHOSH, FAKHRUL ALAM, M MAHMUDUZZAMAN, AKM SHAMSUL KABIR, M SAIF \\ UDDOULA, QUAZI TARIKUL ISLAM
}

\begin{abstract}
Introduction: Liver abscess is an important clinical problem in tropical regions of the world. Current assessment of liver abscesses should allow for better understanding of the aetiopathogenesis of the disease. This study was conducted to find the clinical pattern and aetiopathogenesis of liver abscess in patients admitted in Rajshahi Medical College Hospital.

Methodology: The present cross-sectional study was carried out in the Department of Medicine, Rajshahi Medical College Hospital (RMCH) on consecutive 34 patients of liver abscess admitted between the period of July 2002 and June 2003. Detailed history and clinical examination were performed in all patients. All routine investigations were done. Liver abscess was confirmed by ultrasonography (USG). Aspiration of liver abscess was done under sonographic guidance in the Nuclear Medicine Department of RMCH to diagnose the cause of liver abscess. Aspirated materials were sent for microscopical examination and culture and sensitivity in the Department of Microbiology of the same Institute.

Result: The findings showed that early middle-aged population were usually affected by liver abscess followed by middle aged (mean age around 40 years). The patients were predominantly male with males being 16 times more likely to suffer from the disease than the females. Most of the patients belong to low socioeconomic status (82.4\%). All patients had fever and malaise. Other common manifestations were loss of appetite, lump in the abdomen, intercostal tenderness, nausea/ vomiting, loss of weight. Less common presentations were diarrhoea (29.4\%), jaundice (23.5\%), cough (11.8\%), chest pain (11.8\%) and breathlessness (2.9\%). Liver span of the patients measured by ultra-sonogram showed hepatomegaly in all cases. All patients with pyogenic liver abscess and $75 \%$ of the patients with amoebic abscess had the history of prolonged intake of fermented palm juice (palm wine). Microscopic examination of the pus/aspirate drawn from the liver revealed trophozoite in $7(20.6 \%)$ cases. However, on culture of the specimen, 12(35.3\%) were culture positive and 22(64.7\%) were culture negative.
\end{abstract}

Conclusion: Middle-aged male with low socioeconomic status with the history of prolonged palm wine intake are the most common characteristic of patients with liver abscess. Multi-center study with large sample size is recommended to verify the findings of the present study.

Key word: Clinical pattern, liver abscess; palm wine (Tarii).

\section{Introduction:}

Liver abscess is an important clinical problem in tropical region of the world and account for a high number of hospital admissions. It is usually an easily treatable condition with good clinical outcomes. There is however potential for morbidity and even mortality if proper and timely treatment is not provided ${ }^{1}$. At the beginning of the $19^{\text {th }}$ century, the mortality from liver abscess was $100 \%$. Surgical drainage reduced the mortality from 50 to $75 \%$ by 1930 . With the advent of antibiotics, the reduction in mortality was further geared up, but there was little change in mortality during the next 25 years until 1960 when adoption of special localization techniques promised a great

1. Asst Professor, Department of Gastroenterology, Bangabandhu Sheikh Mujib Medical University (BSMMU), Dhaka.

2. Associate Professor, Medicine, Holly Family Red Crescent Medical College, Dhaka.

3. Asst. Professor, Department of Gastroenterology, Mymensingh Medical College, Mymensingh.

4. Associate Professor, Medicine, Holly Family Red Crescent Medical College, Dhaka.

5. Asst. Professor, Department of Gastroenterology, Mymensingh Medical College, Mymensingh.

6. Professor of Medicine, Popular Medical College, Dhaka.

Correspondence: Dr. Chanchal Kumar Ghosh, Mobile: 01711-855075, E-mail: dr.chanchalghosh@gmail.com

Bangladesh J Medicine 2015; 26 : 55-60 
improvement in its treatment ${ }^{2}$. Mortality rates have decreased substantially over the past several decades, with recent studies reporting rates of $11-31 \%^{3}$; however mortality is higher in older and diabetic patients ${ }^{4}$. In the past pyogenic liver abscess was most commonly seen in children or young adults in association with appendicitis ${ }^{5}$. Although the commonest cause of liver abscess worldwide is amoebiasis, in the developed world pyogenic causes are of increasing importance ${ }^{5,6}$. In the United States, pyogenic liver abscess are important because they are potentially curable and inevitably fatal if untreated.

Amoebiasis caused by Entamoeba histolytica is one of the most common parasitic infections of mankind ${ }^{7}$. Amoebic liver abscess (ALA) is the most common extra intestinal manifestation of infection ${ }^{7,8}$ the incidence of which is $3-9 \%{ }^{9}$. ALA is caused by hematogenous spread of the invasive trophozoites from the colon, which reaches the liver via the portal vain.

Classically there is upper abdominal pain, swinging pyrexia, anorexia, malaise and weight loss. However, in many older patients the symptoms and signs may be much less dramatic, and pain and hepatomegaly may not be present, which presents as so-called pyrexia of unknown origin ${ }^{5}$. Patients may also present with underlying biliary disease with obstructive jaundice. The high swinging fever, chills, and right upper quadrant pain or tenderness are noticeable. The abscess is usually found in the right hepatic lobe $(70 \%)^{3}$.

The dominant organisms isolated from hepatic abscesses have changed over recent years. Whereas aerobic Gram-negative organisms, especially E. coli, used to predominate, anaerobes, particularly Streptococcus milleri, are now found in up to $50 \%$ of abscesses. Mixed infections are identified in about one-third of cases ${ }^{5}$. The diagnosis is usually reached by history and clinical examination together with ultrasonography of liver which will show the abscess. Percutaneous drainage is also helpful to differentiate amoebic from a pyogenic liver abscess ${ }^{10}$. The present study was conducted to find out the clinical pattern of liver abscess among patients admitted in the Department of the Medicine of Rajshahi Medical College Hospital (RMCH). The data derived from the study would facilitate better understanding of aetiopathogenesis of the disease, which in turn, would help improve the management of the disease among Bangladeshi population.

\section{Materials and methods}

34 consecutive patients with liver abscess admitted in the Department of Medicine of Rajshahi Medical
College between July 2002 to June 2003 were studied. The diagnosis was based on clinical features, evidence from imaging studies (e.g. single or multiple spaceoccupying lesions on liver ultrasonography or CT), physical examination of pus from liver aspirates, microscopic examination and culture of the pus and resolution of the lesion (s) after antimicrobial chemotherapy. The presence of reddish-brown pasty aspirate ("anchovy sauce") from aspirated material is typical for amoebic abscess. The demographic characteristics, aetio-pathogenic factors, clinical features, size, number and lobar distribution of the lesions,laboratory data, microbiological findings, methods of treatment and final outcome of each patient was looked for. Presumed aetiologies were assigned according to available imaging, clinical, pathological and surgical information. Duration of symptoms, clinical manifestations and associated diseases were recorded. Of the investigations done were white blood cell count, hemoglobin level, liver function tests, blood urea nitrogen (BUN), serum creatinine, serum albumin, prothrombin time and activated partial thromboplastin time. Imaging techniques/modalities used in the diagnosis of the disease were chest X-ray, plain X-ray abdomen, ultrasonography and CT scan. Sonography and CT scans are capable of diagnosing gas-forming liver abscesses, with gas seen in the abscess before aspiration or drainage. Aspiration of liver abscess was done under sonographic guidance in the Nuclear Medicine Department of $\mathrm{RMCH}$. Aspirated materials were sent to Pathology Department for microscopic examination and for culture and sensitivity.Serologic tests though it is sensitive (95\%) and specific (90\%) were not done due to unavailability of the tests in the institute.

\section{Result}

Over half $(52.9 \%)$ of the patients were early middle aged (31 - 40 years) followed by $29.4 \%$ middle aged ( $41-50$ years), $11.8 \%$ late middle aged $>50$ years and $5.9 \% 21$ to 30 years. The mean age of the patients was $40.2 \pm 4.5$ years (range: $21-56$ years). A male predominance $(94.1 \%)$ was observed in the series with male:female ratio being $16: 1$. In terms of socioeconomic status, most $(82.4 \%)$ of the patients belonged to lower class and the rest $(17.6 \%)$ to middle class. Fever (100\%) was invariably complained by the patients followed by abdominal pain (94.1\%), loss of appetite (94.1\%), intercostal tenderness (73.5\%), lump in the abdomen (70.5\%), nausea/vomiting (52.9\%) and loss of weight $(47.1 \%)$. Other clinical presentations 
were diarrhea (29.4\%), jaundice (23.5\%), cough (11.8\%), chest pain (11.8\%) and breathlessness (2.9\%). Liver span measured by ultra-sonogram shows that $7(20.6 \%)$ had liver span within 12.5 to $15.5 \mathrm{~cm}$ and $15(44.1 \%)$ within 15.6 to $18.5 \mathrm{~cm}$ and $12(35.3 \%)$ had liver span $18.6 \mathrm{~cm}$ or more. Number of abscess cavities in the liver diagnosed by ultra-sonogram showed that $16(47.1 \%)$ had single cavity and $18(52.9 \%)$ had multiple cavities. History of taking local palm wine was present in $85 \%$ (29) patients. All the 14 patients with pyogenic abscess and $75 \%$ (15 out of $20)$ of the patients with amoebic abscess had the history of prolonged palm wine intake. Microscopic examination of the pus/aspirate drawn from the liver revealed $7(20.6 \%)$ cases positive for trophozoite. Trophozoites are found only 7 cases (35\%) among 20 cases of amoebic liver abscess diagnosed otherwise probably due to aspiration was done from superficial layer of the cavities. However, on culture of the specimen, $12(35.3 \%)$ were culture positive and $22(64.7 \%)$ were culture negative. Of the 12 culture positive cases, $7(58.3 \%)$ were Gm (-ve) Rods (E.coli,klebsiella,pseudomonas,proteus), 2 (16.7\%) were $\mathrm{Gm}$ (-ve) anaerobic rods (Bacteroids fragilis),2 $(16.7 \%)$ were $\mathrm{Gm}+$ ve cocci (Enterococci, streptococcus milleri) 1 (8.3\%) were +ve anaerobic cocci (anaerobic streptococcus). Liver abscess either amoebic or pyogenic demonstrated their significant association with regular taking of palm wine $(p=0.046)$ (Table ).

\section{Table I}

Distribution of patients by their sociodemographic characteristics $(n=34)$

\begin{tabular}{lcc}
\hline Demographics & Frequency & Percentage \\
\hline Age (Years) & 02 & 05.9 \\
$21-30$ & 18 & 52.9 \\
$31-40$ & 10 & 29.4 \\
$41-50$ & 04 & 11.8 \\
$>50$ & & \\
Sex & 32 & 94.1 \\
Male & 02 & 05.9 \\
Female & & \\
Socioeconomic status & 28 & 82.4 \\
Lower class & 06 & 17.6 \\
Middle class & 00 & 00.0 \\
Higher class & & $56 y+9$
\end{tabular}

Mean \pm SD $=40.2 \pm 4.5$ years; range $=21-56$ years.
Table II

Distribution of patients by clinical presentation $\left(n=34^{*}\right)$

\begin{tabular}{|c|c|c|}
\hline Clinical characteristics & Frequency & Percentage \\
\hline Fever & 34 & 100.0 \\
\hline Abdominal pain & 32 & 94.1 \\
\hline Loss of appetite & 32 & 94.1 \\
\hline Malaise & 34 & 100.0 \\
\hline Lump in the abdomen & 24 & 70.5 \\
\hline Nausea / Vomiting & 18 & 52.9 \\
\hline Loss of weight & 16 & 47.1 \\
\hline Intercostal tenderness & 25 & 73.5 \\
\hline Diarrhoea & 10 & 29.4 \\
\hline Jaundice & 08 & 23.5 \\
\hline Cough & 04 & 11.8 \\
\hline Chest pain & 04 & 11.8 \\
\hline Breathlessness & 01 & 02.9 \\
\hline
\end{tabular}

*Total will not correspond to $100 \%$ for multiple responses

Table III

Distribution of patients by their liver span $(n=34)$

\begin{tabular}{lcc}
\hline Liver span $(\mathrm{cm})$ & Frequency & Percentage \\
\hline $12.5-15.5$ & 07 & 20.6 \\
$15.6-18.5$ & 15 & 44.1 \\
$>18.6$ & 12 & 35.3 \\
\hline
\end{tabular}

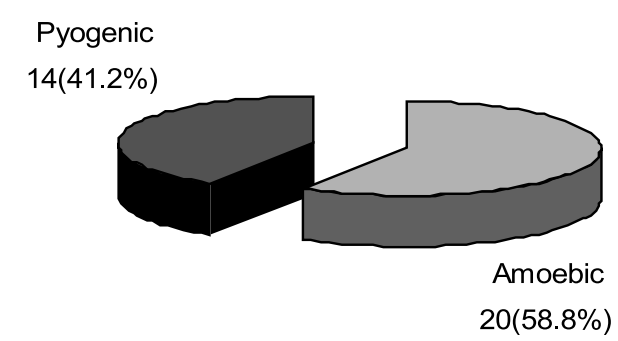

Fig. 1: Distribution of patients by types of liver abscess $(n=34)$

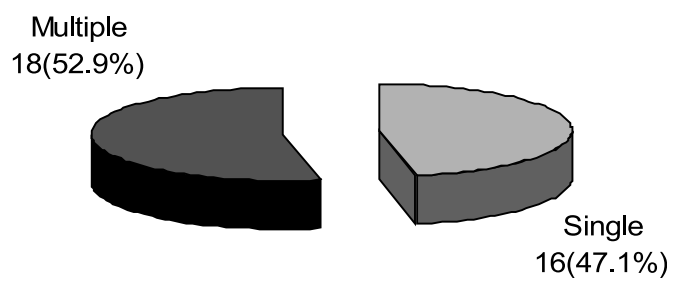

Fig.-2: Distribution of patients by number of abscess cavity $(n=34)$ 
Table IV

Liver abscess and its association with the prolonged palm wine intake $(n=34)$

\begin{tabular}{lcc}
\hline $\begin{array}{l}\text { Types of } \\
\text { abscess }\end{array}$ & $\begin{array}{c}\text { History of } \\
\text { palm wine } \\
\text { intake present }\end{array}$ & $\begin{array}{c}\text { History of } \\
\text { palm wine } \\
\text { intake absent }\end{array}$ \\
\hline Amoebic & $15(75.0)$ & $05(25.0)$ \\
Pyogenic & $14(100.0)$ & $0(00.0)$ \\
\hline
\end{tabular}

Table V

Microscopic examination of the specimen for trophozoite $(n=34)$

\begin{tabular}{lcc}
\hline $\begin{array}{l}\text { Trophozoite in the } \\
\text { specimen }\end{array}$ & Frequency & Percentage \\
\hline Present & 07 & 20.6 \\
Trophozoite negative & 27 & 79.4 \\
\hline
\end{tabular}

Table VI

Culture of the specimen $(n=34)$

\begin{tabular}{lcc}
\hline Culture of the specimen & Frequency & Percentage \\
\hline Culture positive & 12 & 35.3 \\
\hline $\begin{array}{l}\text { (E.coli,klebsiella,proteus, } \\
\text { pseudomonas, enterococci, }\end{array}$ & & \\
strep.milleri, bacteroides, & & \\
anerobic stretto) & & \\
Culture negative & 22 & 64.7 \\
\hline
\end{tabular}

Table VII

Microorganism found in culture positive specimen ( $n=12)$

\begin{tabular}{lcc}
\hline Microorganism & Frequency & Percentage \\
\hline Gm (-ve) Rods & 07 & 58.3 \\
Gm (-ve) anaerobic rods & 02 & 16.7 \\
Gm (+ve) cocci & 02 & 16.7 \\
Gm (+ve) anaerobic cocci & 01 & 08.3 \\
\hline
\end{tabular}

Table VIII

Association between liver abscess with history of taking palm wine

\begin{tabular}{|c|c|c|c|}
\hline \multirow{2}{*}{$\begin{array}{l}\text { Type of liver } \\
\text { abscess }\end{array}$} & \multicolumn{2}{|c|}{ History of taking palm wine } & \multirow{2}{*}{$\begin{array}{c}\text { p- } \\
\text { value }\end{array}$} \\
\hline & $\begin{array}{c}\text { Yes } \\
(\mathrm{n}=29)\end{array}$ & $\begin{array}{c}\text { No } \\
(\mathrm{n}=5)\end{array}$ & \\
\hline Amoebic & $15(51.7)$ & $5(100.0)$ & 0.046 \\
\hline Pyogenic & $14(48.3)$ & $0(0.0)$ & \\
\hline
\end{tabular}

Figures in the parentheses indicate corresponding percentage

Data were analysed using Fisher's Exact Test.

\section{Discussion}

The findings of the study demonstrate that early middle-aged people were the usual victims of liver abscess followed by middle aged (mean age around 40 years). These two age groups together constitute most of the patients of liver abscess. The disease is also predominantly of male sex with males are 16 times more likely to present with the disease than their female counterparts. Quite consistent the findings of this study Sharma and associates ${ }^{11}$ demonstrates mean age of patients to be $40.5 \pm 2.1$ years and male-female ratio of $7: 1$. Lee et $\mathrm{al}^{12}$ in a study of 69 patients with amoebic liver abscess found men predominated by a ratio of $10: 1$ and most patients were in the range of 30-50 years (the mean age being 45 years). Khee-siang et $\mathrm{al}^{13}$ in a study of 84 however, showed a higher mean age of the patients $(58.2 \pm 13.3$ years) and a male:female ratio of 13:8. Khan and colleagues $^{1}$ in a similar study of 966 patients found a male predominance $(76 \%)$ with mean age of the patients being $43 \pm 17$ years.

Majority of the patients belonged low socioeconomic status $(82.4 \%)$ and the rest to middle class indicating that poverty facilities infection because of low sanitary and hygienic measure adopted by the people of living poverty. Christopher and Miguel $^{8}$ described that suboptimal sewer systems, deficient fertilization practices and irrigation with untreated water, all facilitates the ingestion of infective cysts. In India, due to poor sanitary condition and a lower socioeconomic status, amoebiasis is endemic and amoebic liver abscess accounts for 3.0-9.0\% of all cases of amoebiasis ${ }^{14}$.

Patients with amoebic liver abscess manifest early with abdominal pain and fever with no other signs and symptoms. Coexisting diarrhoea occurs in 30\% cases, but it is extremely rare to find amoebic trophozoites in the stool (Huston, 2006) ${ }^{15}$. In the present study all patients were presented with fever and malaise. Other common manifestations were loss of appetite, lump in the abdomen, intercostal tenderness, nausea/vomiting, loss of weight. Other clinical presentations were diarrhoea (29.4\%), jaundice $(23.5 \%)$, cough $(11.8 \%)$, chest pain $(11.8 \%)$ and breathlessness (2.9\%). Several studies ${ }^{11,13,16}$ reported fever and chills to be the most frequent symptoms, followed by abdominal pain and weight loss. Bugti et $\mathrm{al}^{17}$ in a study showed that over $70 \%$ of the pyogenic liver abscess presented with upper abdominal pain followed by high grade fever (62\%), enlarged tender liver (20\%), jaundice(14\%) and loss of appetite(14\%). Gastrointestinal tract upset like nausea and vomiting were rarely complained by the 
patients. Diarrhoea is found $10 \%$ of the cases. Sharma ${ }^{11}$ found hepatomegaly in $16 \%$ of the cases and a right-sided pleural effusion in $14 \%$ cases and ascites in $5.7 \%$ cases, while Lee et $\mathrm{al}^{12}$ in a study of 69 patients with amoebic liver abscess found fever, abdominal pain, and hepatomegaly to be the most frequent presentation.

Abdominal Ultrasound is the "gold standard" for diagnosing liver abscess ${ }^{18.19}$. Liver span of the patients measured by ultra-sonogram showed hepatomegaly in all cases of our study; of them over one-third (35.3\%) had liver span of $18.6 \mathrm{~cm}$ or more.

In the present study, 59\% cases were diagnosed as amoebic abscess. Khan et $\mathrm{al}^{1}$ in a study of 966 patients with uncomplicated liver abscess found a much higher proportion of cases with amoebic liver abscess (68\%). Pyogenic abscess comprised 21\%, indeterminate $8 \%$ and mixed variety $3 \%$ of the patients. Sharma ${ }^{11}$ showed $65 \%$ patients presented with a right lobe abscess, $13 \%$ with left lobe abscess and $22 \%$ with multiple abscesses in both the lobes. Lee et $\mathrm{al}^{12}$ studied 69 cases of amoebic liver abscess and found $58 \%$ of them with solitary abscesses in the right lobe of the liver. Infection can reach the liver in several ways. Single lesions are more common in the right liver. Amoebic trophozoites emerged from the vegetative cyst in the colon and caecum and invade the bowel mucosa to enter the portal venous radical from where they are carried to the liver via portal vein and multiply rapidly and destroy parenchyma, causing amoebic abscess. This explains the frequent occurrence of abscess in the right hepatic lobe, which receives most of the blood draining the caecum and ascending colon ${ }^{7}$.

Number of abscess cavities in the liver are diagnosed by ultrasonogram. In the present study nearly half (47.1\%) had single cavity and the rest half had multiple cavities in the liver. Sono-graphically, $52 \%$ cases have multiple abscess, 20 - 35\% have abscesses in the left lobe, and the remaining $49-80 \%$ have a solitary abscess in the right lobe ${ }^{18,19}$. Sharma et $\mathrm{al}^{11}$ in their study showed multiple abscess in $72 \%$ cases, a solitary left lobe abscess in $13 \%$ cases and a single right lobe abscess in $65 \%$ of cases. Although, amoebic liver abscess occurs mostly in right lobe, yet considerable variations exist. In an ultra-sonographic analysis of 212 patients of amoebic liver abscess, $16 \%$ had multiple abscesses, 35\% had left lobe abscess and $49 \%$ had solitary abscess in the right lobe $^{18}$.

In the present study history of local palm wine intake were taken in every patient. Among the 20 patients with amoebic abscess, 15(75.0\%) had history of prolonged palm wine intake. All patients with pyogenic abscess had the history of prolonged palm wine intake. Islam and associates in similar study demonstrated that $80 \%(59$ out of 75 ) of their pyogenic liver abscess cases consumed alcohol; of them $56(95 \%)$ took locally prepared alcohol (TARI) indicating a strong association between indigenous alcohol intake and development of pyogenic liver abscess ${ }^{20}$. Tari is made by partial fermentation of palm tree juice in bad hygienic environment may be the source of microorganism for liver abscess. This is highly prevalent among males of lower socioeconomic group.

Microscopic examination of the specimen for trophozoite showed that among the 20 patients with amoebic abscess $7(35 \%)$ were positive for trophozoite. Lee et $\mathrm{al}^{12}$ in a study of 69 patients with amoebic liver abscess, Entamoeba histolytica was found in the stool of $31(44.9 \%)$ patient and in the pus of $39(56.5 \%)$ patients.

The dominant organisms isolated from hepatic abscess have changed over recent years. Whereas aerobic Gram negative organisms, especially E. coli used to predominante, anaerobes, particularly Streptococcus milleri, are now found in up to $50 \%$ of the abscesses. Mixed infections are identified in about one-third of the cases ${ }^{5}$. In the present study over one-third (35.3\%) cases were culture positive. Among the culture-positive cases, Gm -ve Rods were predominant (58.3\%). Other less commonly found organisms were $\mathrm{Gm}$-ve anaerobic rods (16.7\%), Gm +ve cocci (16.7\%) and $\mathrm{Gm}$ +ve anaerobic cocci (8.3\%). Alvarez et $\mathrm{al}^{16}$ in a study of older patients with liver abscess, bacteriological cultures of pus from abscess were positive in $85.7 \%$ of the cases. Aerobes were isolated in 33 and anaerobes in 13. E. coli was the most frequently encountered bacterium, followed by S. milleri. Bacteriological cultures of pus from abscess of younger patients were positive in 36 of 42 cases (85\%); 32 had aerobic organisms and 12 anaerobic organisms. Again, E coli and S. milleri were the most common isolates indicating a similar microbial study as that found in older patients.

Like any other scientific study, the present study has both strengths and limitations. The most commendable finding that is revealed from the study is the association of the patients with intake of palmjuice wine (Tarii), while the limitations of the study lies in its sample size which is too small to generalize the findings to reference population and single center study. 


\section{Conclusion}

Patients of liver abscess are generally middle aged (31-40 years), males and of low socioeconomic condition. In this study most of the patients were in the low socioeconomic condition. Common presentation of liver abscess are fever, malaise, abdominal pain, loss of appetite, lump in the abdomen, intercostal tenderness, nausea/vomiting and loss of weight. Liver abscess was diagnosed by ultrasonogram. All patients with pyogenic abscess and majority of amoebic liver abscess had significant history of chronic palm wine (locally known as Tarii) intake which might be the source of pyogenic and amoebic liver abscesses.

\section{References}

1. Khan R, Hamid S, Abiid S, Jafri W, Abbas Z, Islam M, Shah H, Beg S. Predictive factors for early aspiration in liver abscess. World $\mathrm{J}$ Gastroenterol 2008;14(13):2089-2093.

2. Butler RW, Collier JD, Hayes PC, Liver and biliary tract disease.In Davidson's principles and practice of medicine. Boon NA, Colledge NR, Walker BR, Hunter JAA eds. $20^{\text {th }}$ edition 2006, Edinburgh, Churchill Livingstone, pp. 935-989.

3. Rahimian J, Wilson T, Oram V, Holzman RS. Pyogenic Liver Abscess: Recent Trends in Etiology and Mortality. Clin Infec Dis 2004;39:1654-9.

4. Lee SS, Chen Y, Tsai H, Wann S, Lin H, Huang C et al. Predictors of Septic Metastatic Infection and Mortality among Patients with Klebsiella pneumoniae Liver Abscess. Clin Infec Dis 2008;47:642-50.

5. O'Grady J. liver and biliary tract disease.In Textbook of Medicine.Souhami RL and Moxham J eds. $4^{\text {th }}$ edition, 2002. Edinburgh, Churchill Livingstone, pp. 835-882.

6. Zibari GB, Maguire S, Aultman DF, McMillan RW, McDonald JC. Surgical Infections 2000, 1(1):15-21.

7. Fotedar R, Stark D, Beebe N, Marriott D, Ellis J, Harkness J. Laboratory Diagnosis Technique for Entamoeba Species. Clinical Microbiology Reviews 2007; 20(3):511-532.

8. Christopher WD and Miguel A. Amebic Liver Abscess Southern Medical Journal, pp. 935-989.

9. Zafar A and Ahmed S. Amoebic liver abscess: a comparative study of needle aspiration versus conservative treatment. J Ayub Med Coll Abbottabad 2002; 14(1):10-2.
10. Mohammed AE, Al Karawi MA, Ghandour $Z$. Parasitic disease of the liver and biliary tree. Saudi j Gastroenterol 1997;3:22-8.

11. Sharma N, Sharma A, Varma S, AnupamLal A, VirendraShing V. Amoebic liver abscess in the medical emergency of a North Indian hospital. BMC Research Notes 2010;3:21.

12. Lee KC, Yamazakii O, Hamba H, Sakauue Y, Kiinoshita H, Hiirohashii K, Kubo S. Analysis of 69 patients with amebic liver abscess. Journal of Gastroenterology 1996;31(1):40-5.

13. Khee-siiang $\mathrm{C}$, Wen-liang $\mathrm{Y}$, Chi-lun $\mathrm{T}$, Kuo-chen $\mathrm{C}$, Ching-cheng $\mathrm{H}$, Meng-chih L, Che-kim T. Pyogenic liver abscess caused by Klebsiella pneumonia: analysis of the clinical characteristics and outcomes of 84 patients. Chinese Medical Jaurnal 2007;120(2):136-9.

14. Sharma MP and Sariin SK. Amoebic Liver Abscess in a North Indian Hospital current trends. Brit J CliinPrac 1987;41:789-93.

15. Huston CD: Intestinal Protozoa in Feldman: Sleisenger \& Fordtran's Gastrointestinal and Liver Disease. In Pathophysiology, diagnosis and management. 8th edition. Edited by Feldman M, Friedman LS, Brandt LJ, Sleisenger MH. Saunders Elseviers, Philadelphia; 2006:2414-9.

16. Alvarez JA, Gonzalez JJ, Baldonedo RF, Sanz L, Junco A, Rodrfigues JI, Martinez MD. Pyogenic liver abscess: a comparison of older and younger patients. HPB (Oxford). 2001;3(3):201-6.

17. Bugti QA, Baloch MA, Ashan-ul-wadood, Mulghani AH, Azeem B, Ahmed J. Pyogenic liver abscess: demographic, clinical, radiological and bacteriological characteristics and management strategies. Gomal Journal of Medical Sciences 2005;3(1):10-4.

18. Sharma MP and Ahuja V. Amoebic Liver Abscess. Clinical Mediicine JIACM 2003;4(2): 107-11.

19. Aikat BK, Bhusnurmath SR, Pal AK, Chuttani PN, Dutta DV. Amoebic liver abscess-A cliniicopthologic study.Indian J Med Res 1978;67:381-91.

20. Islam Q T, Ekram A R M S, Ahmed M I, Alim M A, Ahad M A, Haque M A, Uddin M R, Ali A S M S, Haque MA. Pyogenic Liver Abscess and Indigenous Alcohol. TAJ 2005; 18(1): 21-24 